\title{
MANFAAT SENAM NIFAS DITINJAU DARI INVOLUSI UTERI IBU POSTPARTUM
}

\author{
Rati Purnama Sari ${ }^{1}$, Rukzha Triyunita ${ }^{2}$,Buyung Keraman ${ }^{3}$ \\ Poltekkes Kemenkes Padang ${ }^{1}$, Puskesmas Watas Marga ${ }^{2}$, Stikes Tri Mandiri sakti ${ }^{3}$ \\ e-mail: ${ }^{1}$ ratipurnamasari@poltekkespadang.ac.id, ${ }^{2}$ rukhzat@gmail.com
}

\begin{abstract}
One of caring to maximize uterine contraction during the puerperium is by doing postpartum exercise. The purpose of this study was to determine the influence of postpartum exercise on a uteri involution maternal postpartum look for decreasing of fundal height on maternal postpartum. This study was a pre-experimental study using a comparison group design. The population in this study was a postpartum mother who gave birth normally in independent midwifery in the region of Puskesmas Curup, by purposive sampling as 40 people. The intervention group did postpartum exercise, then measured the fundal height used pelymetry. The result of this research got mean of the fundal height of 6-hour postpartum in intervention group $15.20 \mathrm{~cm} \pm 1.88 \mathrm{~cm}$ and $14.45 \pm 1.35 \mathrm{~cm}$ in the control group. Mean of fundal height third day in the intervention group $10.70 \pm 2.13 \mathrm{~cm}$ and $11.95 \pm 1.73 \mathrm{~cm}$ in the control group. Mean of fundal height sixth day in intervention group $6.75 \mathrm{~cm} \pm 1.44 \mathrm{~cm}$ and $9.10 \pm 1.48 \mathrm{~cm}$ in the control group. While mean of fundal height tenth day in intervention group $0.00 \mathrm{~cm}$ and $4.80 \pm 3.05 \mathrm{~cm}$ in the control group. There was a significant difference in the decrease of fundal height between the two groups third day $(p=0.049)$, sixth day $(p=0.00)$, and tenth day $(p=0.00)$. Post partum exercise has an effect on the decrease of fundal height. Decreasing of fundal height were faster in the intervention group than in the control group.
\end{abstract}

Key words: postpartum exercise, fundal height

\begin{abstract}
ABSTRAK
Salah satu asuhan untuk memaksimalkan kontraksi uterus pada masa nifas adalah melaksanakan senam nifas. Tujuan penelitian ini untuk mengetahui pengaruh senam nifas terhadap involusi uteri ibu post partum yang dilihat dari penurunan tinggi fundus uteri (TFU) pada ibu post partum. Penelitian ini merupakan studi pra eksperimen menggunakan desain static group comparison. Populasi pada penelitian ini adalah ibu post partum yang melahirkan normal di BPM dalam wilayah Puskesmas Curup. Pengambilan sampel dengan purposive sampling sebanyak 40 orang. Pengumpulan data dilakukan dengan cara observasi dengan alat pelvimeter. Kelompok intervensi melakukan senam nifas dan kelompok kontrol tidak melakukan senam nifas, kemudian dilakukan pengukuran TFU pada 6 jam post partum, hari ke-3, hari ke- 6 dan hari ke-10 post partum. Analisa menggunakan independent sample t-test. Hasil penelitian didapatkan rata-rata TFU 6 jam post partum pada kelompok intervensi $15.20 \mathrm{~cm} \pm 1.88 \mathrm{~cm}$ dan $14.45 \mathrm{~cm} \pm 1.35 \mathrm{~cm}$ pada kelompok kontrol. Rata-rata TFU hari ke-3 pada kelompok intervensi $10.70 \mathrm{~cm} \pm 2.13 \mathrm{~cm}$ dan $11.95 \mathrm{~cm} \pm 1.73 \mathrm{~cm}$ pada kelompok kontrol. Rata-rata TFU hari ke-6 pada kelompok intervensi $6.75 \mathrm{~cm} \pm 1.44 \mathrm{~cm}$ dan $9.10 \mathrm{~cm} \pm 1.483 \mathrm{~cm}$ pada kelompok kontrol. Sedangkan rata-rata TFU hari ke-10 pada kelompok intervensi $0.00 \mathrm{~cm} \pm 0.00 \mathrm{~cm}$ dan $4.80 \mathrm{~cm} \pm 3.05 \mathrm{~cm}$ pada kelompok kontrol. Terdapat perbedaan yang signifikan penurunan tinggi fundus uteri antara kedua kelompok pada hari ke-3 ( $\mathrm{p}=0.049)$, hari ke $6(\mathrm{p}=0.00)$. dan hari ke-10 $(\mathrm{p}=0.00)$. Disimpulkan bahwa senam nifas berpengaruh terhadap penurunan tinggi fundus uteri. Penurunan tinggi fundus uteri lebih cepat pada kelompok intervensi dibandingkan dengan kelompok kontrol.
\end{abstract}

Kata kunci: senam nifas; tinggi fundus uteri

\section{PENDAHULUAN}

Masa nifas atau masa puerperium adalah masa setelah persalinan selesai sampai 6 minggu atau 42 hari. Selama masa nifas, organ reproduksi secara perlahan akan mengalami perubahan seperti keadaan sebelum hamil. Perubahan organ reproduksi ini disebut involusi. Asuhan selama periode nifas perlu mendapat perhatian karena sekitar $60 \%$ Angka Kematian. Ibu terjadi pada periode ini. Perdarahan merupakan penyebab utama kesakitan dan kematian ibu pada masa nifas, dimana 50\%-60\% karena kegagalan uterus berkontraksi secara sempurna. $^{(1)}$

Menurut laporan World Health Organization (WHO) tahun 2014 Angka Kematian Ibu (AKI) di dunia yaitu 289.000 jiwa. Beberapa negara memiliki AKI cukup tinggi seperti Afrika Sub-Saharan 179.000 jiwa, Asia Selatan 69.000 jiwa, dan Asia Tenggara 16.000 jiwa. Di Indonesia AKI masih cukup tinggi. Menurut SDKI tahun 2012 menunjukkan peningkatan AKI yang signifikan yaitu menjadi 359 kematian ibu per 100.000 kelahiran hidup. AKI kembali 
menunjukkan penurunan menjadi 305 kematian ibu per 100.000 kelahiran hidup berdasarkan hasil Survei Penduduk Antar Sensus (SUPAS) 2015. Angka kematian ibu terbesar terjadi pada masa nifas. ${ }^{(2)}$

Di provinsi Bengkulu AKI sebesar 137 per 100.000 KH. Dan kematian ibu tertinggi terjadi pada ibu nifas yakni mencapai $43 \%$ dari semua kematian ibu. Di provinsi Bengkulu pada tahun tahun 2015 secara absolut jumlah kematian ibu sebanyak 49 orang yang terdiri dari kematian ibu hamil sebanyak 7 orang, kematian ibu bersalin sebanyak 13 orang, dan kematian ibu nifas sebanyak 21 orang. ${ }^{(3)}$

Di kabupaten Rejang Lebong kematian ibu nifas menempati posisi teratas dari semua kematian ibu. Laporan analisa data Kesehatan Ibu dan Anak (KIA) Dinas Kesehatan kabupaten Rejang Lebong pada tahun 2016 terdapat AKI sebanyak 5 orang dengan rincian kematian ibu hamil 1 orang (20\%), kematian ibu bersalin 1 orang (20\%) dan kematian ibu nifas sebanyak 3 orang $(60 \%)$. Penyebab kematian ibu terbanyak adalah karena hipertensi dalam kehamilan sebanyak 2 orang (40\%), infeksi 1 orang $(20 \%)$ dan oleh sebab lain sebanyak 2 orang $(40 \%)$. ${ }^{(4)}$

Berdasarkan studi pendahuluan yang penulis lakukan pada tahun 2017 di Kabupaten Rejang Lebong terdapat 21 puskesmas. Dari 21 puskesmas tersebut angka komplikasi maternal tertinggi terdapat di puskesmas Curup dan terendah di puskesmas Beringin Tiga. Diantara ibu yang mengalami komplikasi maternal di puskesmas Curup tersebut ditemukan 8 orang ibu nifas dari 3 BPM yang mengalami masalah subinvolusi uteri dari keseluruhan ibu bersalin yang berjumlah 755 orang. Dan dari semua ibu nifas yang mengalami subinvolusi uteri tersebut tidak ada yang melakukan senam nifas.

\section{METODE}

Penelitian ini dilakukan di 13 BPM (Bidan Praktek Mandiri) dalam Wilayah Puskesmas Curup, Kabupaten Rejang Lebong, Provinsi Bengkulu. Penelitian ini dilakukan dari tanggal 4 April 2018 sampai dengan tanggal 2 Juni 2018. Desain penelitian yang digunakan dalam penelitian ini adalah pra eksperimen static group comparison. Adapun populasi pada penelitian ini adalah ibu post partum yang melahirkan normal di BPM dalam wilayah Puskesmas Curup tahun 2017 yang berjumlah 775 orang. Berdasarkan data tapsiran persalinan ibu hamil yang perkiraan melahirkannya pada bulan April sampai dengan bulan Juni 2018 sebanyak 175 orang. Sampel dalam penelitian ini adalah ibu post partum yang melahirkan normal di BPM dalam wilayah Puskesmas Curup yang memenuhi kriteria pengambilan sampel. Sampel diambil dengan teknik purposive sampling. Pengumpulan data dengan observasi. Tehnik analisis data dilakukan dengan analisis univariat dan bivariat, sebelum melakukan analisis data dilakukan uji prasyarat analisis dengan menggunakan uji normalitas dan uji homogenitas. Uji statistik yang digunakan adalah independent sample t-test.

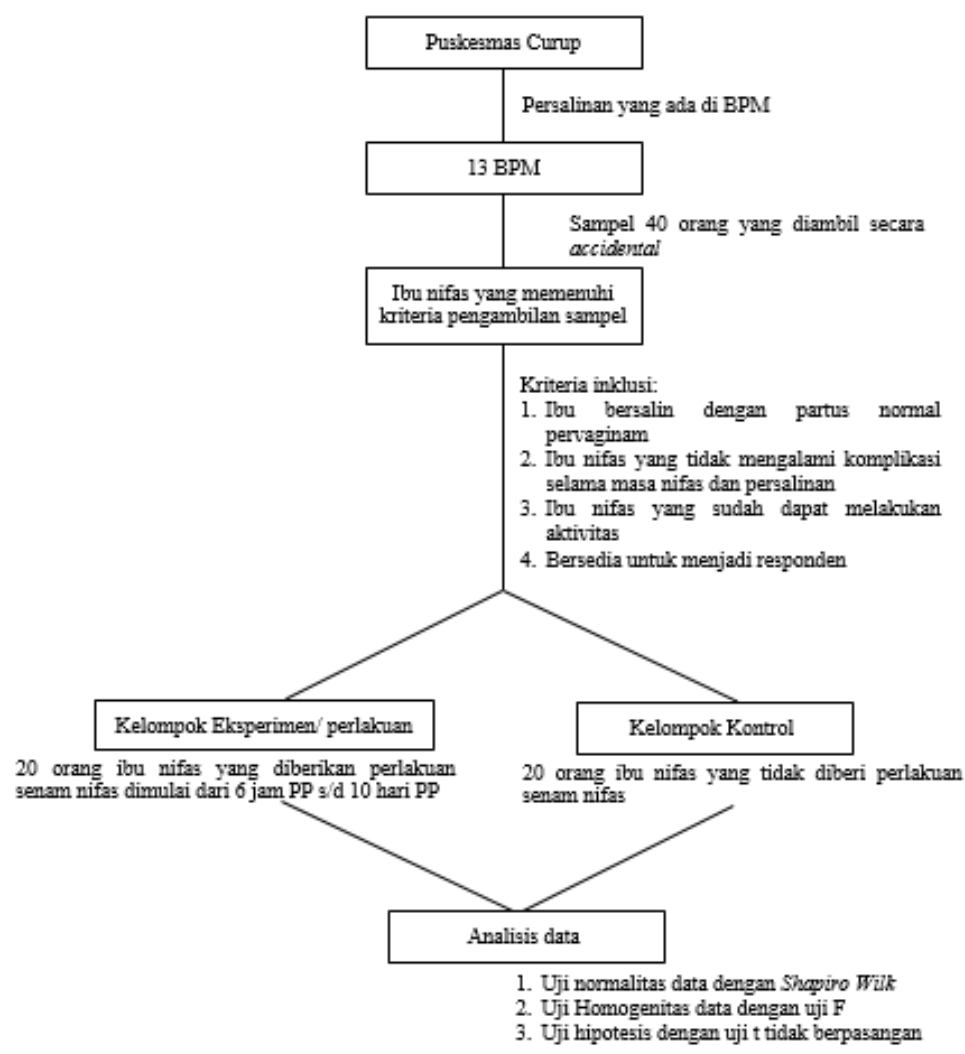

Gambar 1. Bagan Alur Penelitian

\section{HASIL}

1. Analisis univariat

Analisis univariat berupa data tinggi fundus uteri ibu nifas pada 6 jam post partum (PP), 3 hari PP, 6 hari PP dan 10 hari PP, disajikan pada tabel berikut ini:

Tabel 1. Tabel Penurunan Tinggi Fundus Uteri

\begin{tabular}{|c|c|c|c|}
\hline No. & Variabel & $\begin{array}{l}\text { Kelompok } \\
\text { Intervensi }\end{array}$ & $\begin{array}{c}\text { Kelompok } \\
\text { Kontrol }\end{array}$ \\
\hline 1. & $\begin{array}{l}\text { TFU } 6 \text { jam PP }(\mathrm{cm}) \\
\text { - Minimun } \\
\text { - Maksimun } \\
\text { - Mean } \pm \text { SD }\end{array}$ & $\begin{array}{c}11 \\
18 \\
15.20 \pm 1.88\end{array}$ & $\begin{array}{c}12 \\
16 \\
14.45 \pm 1.35\end{array}$ \\
\hline 2. & $\begin{array}{l}\text { TFU } 3 \text { Hari PP }(\mathrm{cm}) \\
\text { - Minimun } \\
\text { - Maksimun } \\
\text { - Mean } \pm \text { SD }\end{array}$ & $\begin{array}{c}8 \\
16 \\
10.70 \pm 2.13\end{array}$ & $\begin{array}{c}9 \\
16 \\
11.95 \pm 1.73\end{array}$ \\
\hline No. & Variabel & $\begin{array}{l}\text { Kelompok } \\
\text { Intervensi }\end{array}$ & $\begin{array}{c}\text { Kelompok } \\
\text { Kontrol }\end{array}$ \\
\hline 3. & $\begin{array}{l}\text { TFU 6 Hari PP }(\mathrm{cm}) \\
\text { - Minimun } \\
\text { - Maksimun }\end{array}$ & $\begin{array}{l}5 \\
9\end{array}$ & $\begin{array}{c}6 \\
11\end{array}$ \\
\hline
\end{tabular}




\begin{tabular}{|l|l|c|c|}
\hline & - Mean \pm SD & $6.75 \pm 1.44$ & $9.10 \pm 1.48$ \\
\hline 4. & TFU 10 Hari PP & & \\
& $(\mathrm{cm})$ & 0 & 0 \\
& - Minimun & 0.00 & $4.80 \pm 3.05$ \\
& - Maksimun & & \\
& - Mean \pm SD & & \\
\hline
\end{tabular}

Berdasarkan analisis data dengan statistik deskriptif dari masing-masing kelompok dapat dilihat sebagai berikut:

a) Pada 6 jam PP rata-rata tinggi fundus uteri kelompok intervensi adalah $15.20 \mathrm{~cm} \pm 1.88 \mathrm{~cm}$ dengan tinggi fundus uteri minimum $11 \mathrm{~cm}$ dan maksimum $18 \mathrm{~cm}$, sedangkan rata-rata tinggi fundus uteri untuk kelompok kontrol adalah 14.45 $\mathrm{cm} \pm 1.35 \mathrm{~cm}$ dengan tinggi fundus uteri minimum $12 \mathrm{~cm}$ dan tinggi fundus uteri maksimum $16 \mathrm{~cm}$.

b) Pada 3 hari PP rata-rata tinggi fundus uteri kelompok intervensi adalah $10.70 \mathrm{~cm} \pm 2.13 \mathrm{~cm}$ dengan tinggi fundus uteri minimum $8 \mathrm{~cm}$ dan maksimum $16 \mathrm{~cm}$, sedangkan rata-rata tinggi fundus uteri untuk kelompok kontrol adalah 11.95 $\mathrm{cm} \pm 1.73 \mathrm{~cm}$ dengan tinggi fundus uteri minimum $9 \mathrm{~cm}$ dan tinggi fundus uteri maksimum $16 \mathrm{~cm}$.

c) Pada 6 hari PP rata-rata tinggi fundus uteri kelompok intervensi adalah $6.75 \mathrm{~cm} \pm 1.44 \mathrm{~cm}$ dengan tinggi fundus uteri minimum $5 \mathrm{~cm}$ dan maksimum $9 \mathrm{~cm}$, sedangkan rata-rata tinggi fundus uteri untuk kelompok kontrol adalah 9.10 $\mathrm{cm} \pm 1.48 \mathrm{~cm}$ dengan tinggi fundus uteri minimum $6 \mathrm{~cm}$ dan tinggi fundus uteri maksimum $11 \mathrm{~cm}$.

d) Pada 10 hari PP rata-rata tinggi fundus uteri kelompok intervensi adalah $0.00 \mathrm{~cm} \pm 0.00 \mathrm{~cm}$ dengan tinggi fundus uteri minimum $0 \mathrm{~cm}$ dan maksimum $0 \mathrm{~cm}$, sedangkan rata-rata tinggi fundus uteri untuk kelompok kontrol adalah 4.80 $\mathrm{cm} \pm 3.05 \mathrm{~cm}$ dengan tinggi fundus uteri minimum $0 \mathrm{~cm}$ dan tinggi fundus uteri maksimum $10 \mathrm{~cm}$.

\section{Analisis Bivariat}

Jumlah data valid ada 40, yaitu ibu melahirkan ikut senam nifas (senam nifas teratur) 20 orang dan ibu melahirkan tidak ikut senam nifas teratur 20 orang. Analisis bivariat yang digunakan adalah uji independent sample t-test tidak berpasangan dengan melihat perbedaan selisih rata-rata tinggi fundus uteri antara dua kelompok sampel yang dilakukan secara berkala yaitu pada hari ke-3 PP, hari ke-6 PP dan hari ke-10 PP. Hasil uji independent sample t-test disajikan pada tabel berikut ini:

Tabel 2. Independent Sample T-Test 3 hari PP, 6 hari $\mathrm{PP}$ dan 10 hari PP

\begin{tabular}{|c|c|c|c|c|}
\hline Variabel & $\mathrm{F}$ & $\mathrm{p}$-value & $\mathrm{t}$ & $\mathrm{p}$-value \\
\hline $\begin{array}{c}\text { TFU 3 hari } \\
\text { PP }\end{array}$ & 0.572 & 0.454 & 2.037 & 0.049 \\
\hline $\begin{array}{c}\text { TFU 6 hari } \\
\text { PP }\end{array}$ & 0.748 & 0.393 & 5.073 & 0.000 \\
\hline $\begin{array}{c}\text { TFU 10 } \\
\text { hari PP }\end{array}$ & 38.92 & 0.000 & 7.029 & 0.000 \\
\hline
\end{tabular}

Berdasarkan tabel diatas, analisis data TFU pada hari ke-3 didapat nilai $\mathrm{F}=0.572$ dengan nilai $p$ value $=0,454>\alpha=0,05$, maka kedua kelompok memiliki varian yang sama. Berdasarkan analisis didapat nilai $\mathrm{t}=2,037$ dengan $p$-value $0,049<0,05$, maka Ho ditolak dan $\mathrm{Ha}$ diterima. Jadi senam nifas berpengaruh terhadap proses involusi uteri ibu post partum.

Kemudian analisis data TFU pada hari ke-6 didapat nilai $\mathrm{F}=0.748$ dengan nilai $p$-value $=0,393>\alpha=0,05$, maka kedua kelompok memiliki varian yang sama. Berdasarkan analisis didapat nilai $\mathrm{t}=5.073$ dengan $p$-value $0,000<0,05$, maka Ho ditolak dan Ha diterima. Jadi senam nifas berpengaruh terhadap proses involusi uteri ibu post partum.

Selanjutnya analisis data TFU pada hari ke-10 didapat nilai $\mathrm{F}=38.920$ dengan nilai p-value $=0,00<\alpha=0,05$, maka kedua kelompok memiliki varian yang tidak sama. Berdasarkan analisis didapat nilai $\mathrm{t}=7.029$ dengan $p$-value $0,000<\alpha=0,05$, maka Ho ditolak dan Ha diterima. Jadi senam nifas berpengaruh terhadap proses involusi uteri ibu post partum.

Berdasarkan hasil uji Independent Sample TTest ada pengaruh yang signifikan senam nifas terhadap proses involusi uteri ibu post partum yang bersalin di BPM dalam wilayah puskesmas Curup. Berdasarkan hasil pengukuran tinggi fundus uteri baik pada kelompok intervensi maupun pada kelompok kontrol, terlihat penurunan tinggi fundus uteri setiap harinya. Hal ini terlihat dari nilai rata-rata tinggi fundus uteri setelah hari ke-3, ke-6 dan hari ke-10 post partum. Terlihat perbedaan penurunan TFU antara kelompok intervensi dengan kelompok kontrol. Penurunan TFU pada kelompok intervensi lebih cepat dibandingkan pada kelompok kontrol. Hal ini menunjukkan kelompok yang diberi intervensi senam nifas secara teratur terjadi penurunan TFU yang sangat signifikan dibandingkan dengan kelompok kontrol yang tidak melakukan senam nifas.

\section{PEMBAHASAN}

Berdasarkan hasil pengukuran tinggi fundus uteri baik pada kelompok intervensi maupun pada kelompok kontrol, terlihat penurunan tinggi fundus uteri setiap harinya. Hal ini terlihat dari nilai rata-rata tinggi fundus uteri setelah hari ke-3, ke-6 dan hari ke10 post partum. Keadaan ini menggambarkan bahwa semakin bertambah hari post partum semakin turun TFU. Hal ini terjadi oleh karena setelah melahirkan, uterus akan kembali ke keadaan sebelum hamil yang disebut dengan involusi.

Proses Involusi berdasarkan pengukuran TFU awal pada 6 jam post partum dengan pengukuran TFU hari ke-3 terdapat perbedaan nilai rata-rata penurunan fundus uteri antara kelompok intervensi dengan kelompok kontrol. Pada kelompok intervensi TFU rata-rata $10.70 \mathrm{~cm} \pm 2.13 \quad \mathrm{~cm}$ sedangkan pada kelompok kontrol rata-rata $11.95 \mathrm{~cm} \pm 1.731 \mathrm{~cm}$. Penurunan TFU kelompok intervensi lebih cepat dari 
pada kelompok kontrol. Pada kelompok kontrol yang tidak melakukan senam nifas secara teratur TFU nya terlihat turun namun tidak secepat penurunan TFU pada kelompok yang melakukan senam nifas.

Demikian juga pada pengukuran TFU hari ke6. Rata-rata TFU pada kelompok intervensi $6.75 \mathrm{~cm}$ $\pm 1.446 \mathrm{~cm}$, sementara pada kelompok kontrol rata-rata TFU $9.10 \mathrm{~cm} \pm 1.483 \mathrm{~cm}$. Terdapat perbedaan penurunan rata-rata TFU, kelompok intervensi lebih cepat penurunan TFU nya dibandingkan dengan kelompok kontrol. Senam nifas berpengaruh terhadap involusi uteri dan ini terlihat pada kontrol tetap terjadi penurunan TFU namun penurunan TFU nya lebih lambat dibandingkan pada kelompok yang melakukan senam nifas secara teratur hal ini terlihat dari perbedaan TFU antara kelompok intervensi dengan kelompok kontrol.

Pada pengukuran TFU hari ke-10 post partum pada kelompok intervensi nilai rata-rata TFU adalah $0.00 \mathrm{~cm} \pm 0.00 \mathrm{~cm}$ atau tidak teraba lagi, sementara pada kelompok kontrol nilai rata-rata TFU adalah 4.80 $\mathrm{cm} \pm 3.054 \mathrm{~cm}$. Hal ini menunjukkan perbedaan penurunan TFU antara kedua kelompok. Penurunan TFU pada kelompok intervensi lebih cepat dibandingkan pada kelompok kontrol. Hal ini menunjukkan kelompok yang diberi intervensi senam nifas terjadi penurunan TFU yang sangat signifikan dibandingkan dengan kelompok kontrol yang tidak melakukan senam nifas.

Rata-rata tinggi fundus uteri antara kelompok intervensi dan kelompok kontrol terjadi penurunan. Penurunan TFU terjadi karena proses involusi uterus yaitu setelah bayi dilahirkan, uterus yang selama persalinan mengalami kontraksi dan retraksi akan menjadi keras sehingga dapat menutup pembuluh darah besar yang bermuara pada bekas implantasi plasenta. Pada hari pertama ibu post partum tinggi fundus uteri kira-kira satu jari bawah pusat $(1 \mathrm{~cm})$. Pada hari kelima post partum uterus menjadi $1 / 3$ jarak antara symphisis ke pusat. Dan hari ke 14 fundus uteri sukar diraba di atas symphisis. Tinggi fundus uteri menurun $1 \mathrm{~cm}$ tiap hari. Secara berangsur-angsur menjadi kecil (involusi) hingga akhirnya kembali seperti sebelum hamil. ${ }^{(5)}$

Pelaksanaan senam nifas secara teratur sesuai dengan teknik yang diajarkan membantu mempercepat pemulihan kondisi ibu, mempercepat proses involusi uteri, membantu pemulihan dan mengencangkan otot panggul, perut, dan perineum, memperlancar pengeluaran lochea, membantu mengurangi rasa sakit dan mengurangi resiko komplikasi. ${ }^{(6)}$ Senam nifas yang dilakukan tepat waktu secara bertahap hari demi hari, akan membuahkan hasil yang maksimal dan dapat mempengaruhi involusi uteri sebagaimana tujuan dari senam nifas antara lain dapat mempercepat proses involusi uteri memperlancar pengeluaran lochea. ${ }^{(7)}$

Senam nifas sebagai salah satu bentuk latihan fisik, akan memberi dampak terhadap sistem kardiovaskuler, aliran darah otot dan curah jantung meningkat begitu pula pada sistim pernafasan dan sistem metabolik dalam perubahan ATP dan ADP dengan pelepasan energi ke otot untuk berkontraksi. ${ }^{\left({ }^{(}\right)}$ Kontraksi pada uterus akan mempercepat proses involusi uterus yaitu perubahan retrogresif pada uterus yang menyebabkan berkurangnya ukuran uterus. Uterus yang berkontraksi dengan baik secara bertahap akan berkurang ukurannnya, sampai tidak dapat dipalpasi lagi diatas simpisis pubis. ${ }^{(9)}$

Penelitian ini sejalan dengan penelitian yang dilakukan oleh di RSUP DR. M. Djamil Padang yang menunjukkan ada pengaruh senam nifas terhadap penurunan tinggi fundus uteri pada ibu post partum. Penurunan tinggi fundus uteri lebih cepat pada kelompok senam nifas dibandingkan dengan kelompok yang tidak senam nifas, yang sangat bermakna secara statistik. $^{(10)}$ Demikian juga dengan penelitian yang dilakukan oleh di RS Dr. Soeroeto Ngawi dengan hasil penelitian ada pengaruh signifikan senam nifas terhadap proses involusi uteri pada ibu postpartum. ${ }^{(11)}$

Hasil yang sama juga didapatkan dari penelitian yang dilakukan di wilayah Puskesmas Borobudur Kabupaten Magelang yang menunjukkan ada perbedaan proses involusi uteri pada ibu yang melaksanakan dan tidak melaksanakan senam nifas, penurunan rata-rata TFU lebih cepat pada kelompok yang melakukan senam nifas. ${ }^{(12)}$ Demikian juga halnya dengan penelitian yang dilakukan di wilayah kerja puskesmas Rumbai, Riau yang menunjukkan hasil bahwa senam nifas merupakan tindakan yang paling efektif untuk mencapai waktu involusi uteri yang minimal pada ibu postpartum. ${ }^{(13)}$

Penelitian ini menunjukkan bahwa senam nifas akan mempercepat proses involusi uteri pada ibu post partum. Hal ini terlihat dari penurunan tinggi fundus uteri lebih cepat pada kelompok senam nifas yang dilakukan secara teratur dibandingkan dengan kelompok yang tidak melakukan senam nifas atau melakukan senam nifas tapi tidak teratur. Senam nifas dapat mempercepat involusi uteri pada ibu post partum. Pada kelompok intervensi pada hari ke-10 TFU sudah tidak teraba lagi sementara pada kelompok kontrol TFU masih dapat diraba. Hal ini menunjukkan terjadi penurunan TFU yang sangat signifikan pada kelompok intervensi dibandingkan dengan kelompok kontrol. Dengan demikian ada pengaruh senam nifas terhadap proses involusi uteri pada ibu post partum.

\section{KESIMPULAN}

Senam nifas yang dilakukan pada penelitian ini berpengaruh terhadap penurunan tinggi fundus uteri. Penurunan tinggi fundus uteri lebih cepat pada kelompok intervensi dibandingkan dengan kelompok kontrol.

Penelitian lain dapat dilakukan dengan melibatkan lebih banyak responden, tidak hanya meneliti pengaruh senam nifas terhadap involusi uteri 
tetapi juga menambah variabel-variabel lainnya yang juga dapat mempengaruhi involusi uteri ibu post partum seperti status gizi, status menyusui, usia dan paritas.

\section{DAFTAR PUSTAKA}

1. Maritalia, D. Asuhan Kebidanan Nifas dan Menyusui. Yogyakarta: Pustaka Pelajar. 2014.

2. Kementerian Kesehatan RI. Profil Kesehatan Indonesia Tahun 2016. Jakarta: Kementerian Kesehatan RI. 2017.

3. Dinas Kesehatan Provinsi Bengkulu. Profil Kesehatan Provinsi Bengkulu Tahun 2015. Bengkulu: Dinas Kesehatan Provinsi Bengkulu. 2016

4. Dinas Kesehatan Kabupaten Rejang Lebong. Laporan Tahunan Program Kesga Tahun 2016. Rejang Lebong: Dinas Kesehatan Kabupaten Rejang Lebong. 2017

5. Walyani, E., \& Purwoastuti, E. Asuhan Kebidanan Masa Nifas. Bandung: PT Refika Aditama. 2015.

6. Marliandini, Y, \& Ningrum, N. P. Asuhan Kebidanan pada Masa Nifas dan Menyusui. Jakarta: Salemba Medika. 2015

7. Yanti, D., \& Sundawati, D. Asuhan Kebidanan Nifas Belajar Menjadi Bidan Profesional. Bandung: PT Refika Aditama. 2014

8. Widjajakusuma, M.D. 2014. Buku Ajar Fisiologi Kedokteran. Review Of Medical Physiology. Edisi ke-12. Jakarta: EGC

9. Varney, H.,dkk. 2015. Buku Ajar Asuhan Kebidanan. Jakarta: EGC

10. Rullynil, N.T., Ermawati, \& Evareny, L. Pengaruh Senam Nifas terhadap Penurunan Tinggi Fundus Uteri pada Ibu Postpartum di RSUP Dr. M.Djamil Padang. Jurnal Kesehatan Andalas. 2017. diakses dari http://jurnal.fk.unand.ac.id/indeks.php/jka/article/

11. Frilasari, H., \& LadismaKyki. (2014). Pengaruh Senam Nifas Terhadap Proses Involusi Uteri Pada Ibu Post Partum Di RSUD DR. Soeroto Ngawi. Jurnal Penelitian Kesehatan. 2014. Diakses dari http://ejournal.stikesppni.ac.id/index.php/JKS/artic le/view/223

12. Munayarokh, dkk. Proses Involusi Uteri pada Ibu yang Melaksanakan dan Tidak Melaksanakan Senam Nifas di Bidan Praktek Mandiri, JOM. 2015. diakses dari https://media.neliti.com/.../128541-IDproses-involusio-uterus-pada-ibu-yang-me.pdf

13. Lisni, A, dkk. Perbandingan Efektivitas Senam Nifas dan Pijat Oksitosin Terhadap Involusi Uteri Pada Ibu Post Partum. Jurnal Riset Kesehatan. $2015 . \quad$ diakses dari https://media.neliti.com/media/publications/18758 7-ID-none.pdf 